\title{
Mobile Exam Management System using LSA Algorithm
}

\author{
Seror Mohammed Jawad \\ Computer Science Dept. \\ Collage of Science \\ Al- Mustansiriyah University \\ Baghdad, Iraq ,
}

\author{
Karim Q. Hussein, PhD \\ Computer Science Dept. \\ College of Science \\ Al- Mustansiriyah University \\ Baghdad, Iraq,
}

\begin{abstract}
The rapid spread of $3 \mathrm{G}$ wireless network and wireless technologies, are applied in many areas, the education is the interesting approach for using this technique, so the benefit of modern technology can be used in mobile learning. This system is focused on design mobile learning management system which simulates the learning process between teacher and student, by build an educational system that the student can get educational material and procedure MCQ test, open question and analyze student answers and evaluated automatically using modern techniques. Latent semantic analysis (LSA) has been employed in intelligent learning systems for evaluation students' learning by evaluating their answers to questions in the tutoring domain. Latent Semantic Analysis (LSA) is an attempt to solve the problem of Automatically scoring open questions..
\end{abstract}

\section{Keywords}

Mobile learning, Latent Semantic Analysis, LSA, automatically scoring.

\section{INTRODUCTION}

Mobile Learning has become a hot-topic and therefore has been seriously laden with marketing and hype. M-learning is different from conventional E-Learning. It was the adapting or customizing the content for delivery on mobile devices [1].

The particular aims of this review are [2]: to identify the different variety of mobile technologies that are applicable to education, to encourage educators and technical developers to rethink their roles for the future of learning with mobile technologies.

Using software to evaluate open questions is still a challenge. Therefore, there are many types of multiple choice tests and short answer tasks. But there is no solution available in which students may train their ability to write answers to open questions, as it is required in written exams.

Considering this problem in information retrieval to score an open question seems to be a similar problem. Exam answers should contain important keywords, but contain their own semantic structure also. This Project attempts to rate a student's exam answer by using LSA[3]. Further it is of interest what constraints have to be taken into account to apply LSA for question scoring.

\section{MOTIVATION TOWARDS THIS RESEARCH WORK}

Several items were included to identify what is the motivation of a mobile learning. One of the main motivators is the widespread use of mobile phones and the possibility of providing an advantage in learning anywhere, anytime.

Automatically scoring open questions in widely multiuser virtual courses still an unsolved challenge. Particularly unexpressed semantic structures may be considered problematic for machines. Latent Semantic Analysis (LSA) is an attempt to solve this problem in the field of information retrieval and can be seen as attempt for representing semantic structure.

\section{RELATED WORK}

There are several researches focusing on mobile learning. The summarizations of some related research are listed below:

- Romana Martin (2011) [5]: suggested M-learning and student engagement of Factors that support students' engagement in M-learning.

- $\quad$ Razieh Niazi and Qusay H. Mahmoud [6], "Design and Development of a Device Independent System for Mobile Learning ", This paper concentrated on the design and development of mobile learning systems.Make use of stochastic components.

- L.E. Dyson, R. Raban, A. Litchfield and E. Lawrence [7]," Embedding Mobile Learning into Mainstream Educational Practice: Overcoming the Cost Barrier" In this paper, the embedding of mobile learning into mainstream educational practice is examined, that of the cost.

- Wael H. Gomaa and Aly A. Fahmy (2012): presented the Automatic Scoring (AS) system that is using the texts similarity to evaluate student's answer.

\section{OBJECTIVE OF RESEARCH}

- The goal is to build an integrated learning system that is capable conduct testing for students (exam) and evaluation of student answers without direct intervention from the teacher.

- The general idea of this experiment is to encourage using LSA to rate open questions is functional.

- The use of mobile telephones and the Internet as a platform simulates the learning process and evaluate tests.

\section{TOOLS, SCOPE AND LIMITATION OF RESEARCH}

- The overall objective of this project is to support the idea of applying mobile learning in Iraq because of the current situation that prevent some students from going to schools and universities.

- Building a mobile learning management system is able to evaluate students' answers through the concept of Automatic Question Scoring using one of the Text Similarity algorithms.

- Language handled by the system are the texts of the lessons specific to university students.

- The system works to manage the process of learning and exam between teacher and student at the university. 
- Period, which lasted preparations for the project is one year of collection requirements and information and build the system.

- Algorithm: LSA

- $\quad$ Software: Microsoft Visual Studio .NET.2010

\section{SYSTEM DESCRIPTION}

The general proposed system is depicted in Figure (6). The figure illustrates application processes from both sides admin and users. In general, the system includes two phases.

The application phase, in this phase the system will provide a web interface and allow the admin (Teacher) full control on many functional as add and remove users, also add new exam sheets, set the default sheet for perform exam, and change semantic space. The general user which be the student, access to the tutorials, perform the exam which will be divided to two parts multiple choices question (MCQ), and Plain text exam , finally will get the final degree which the sum of MCQ degrees and Plain text degree.

The second phase to preprocessing in isolation from application, can be implemented outside the application, as a preprocessing or initialization before application start. This phase involves two parts, in one of them prepares the tutorials, questions (MCQ, Plain text) and typical answers for Plain text exam by admin. This periodicity operation whenever the admin need add or change both the lectures and questions as needed. And the other, creates semantic space from large collection of raw texts (corpus).
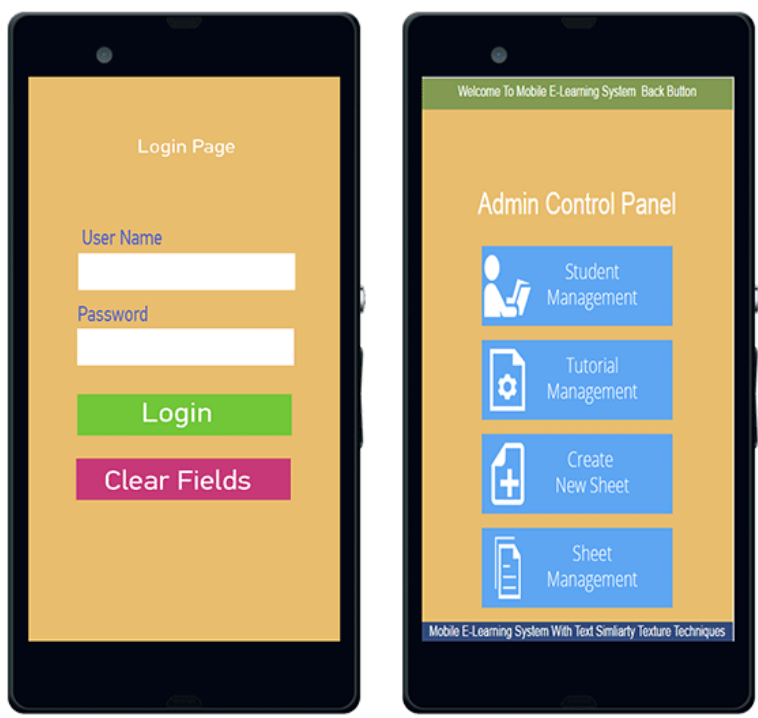
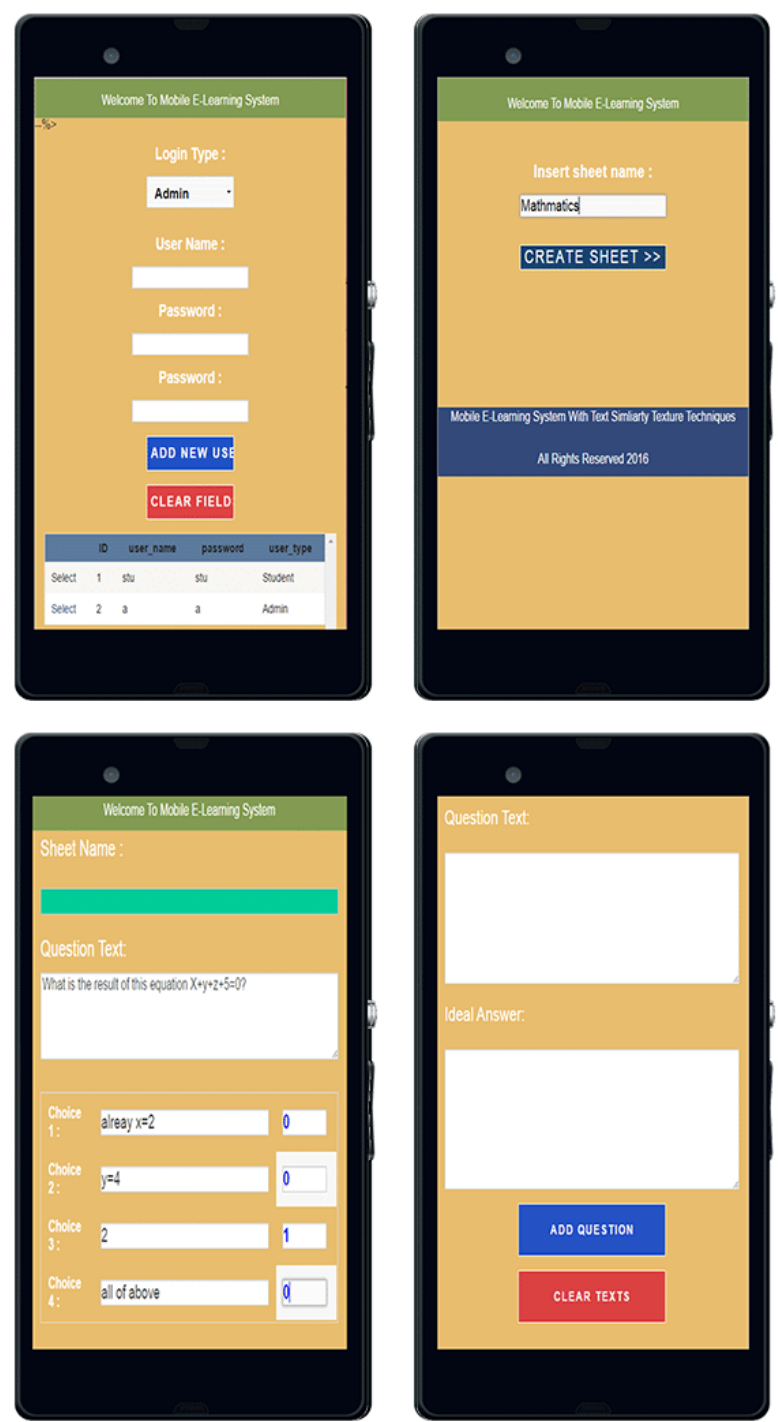

Figure (1):shows the overall organization for the application 


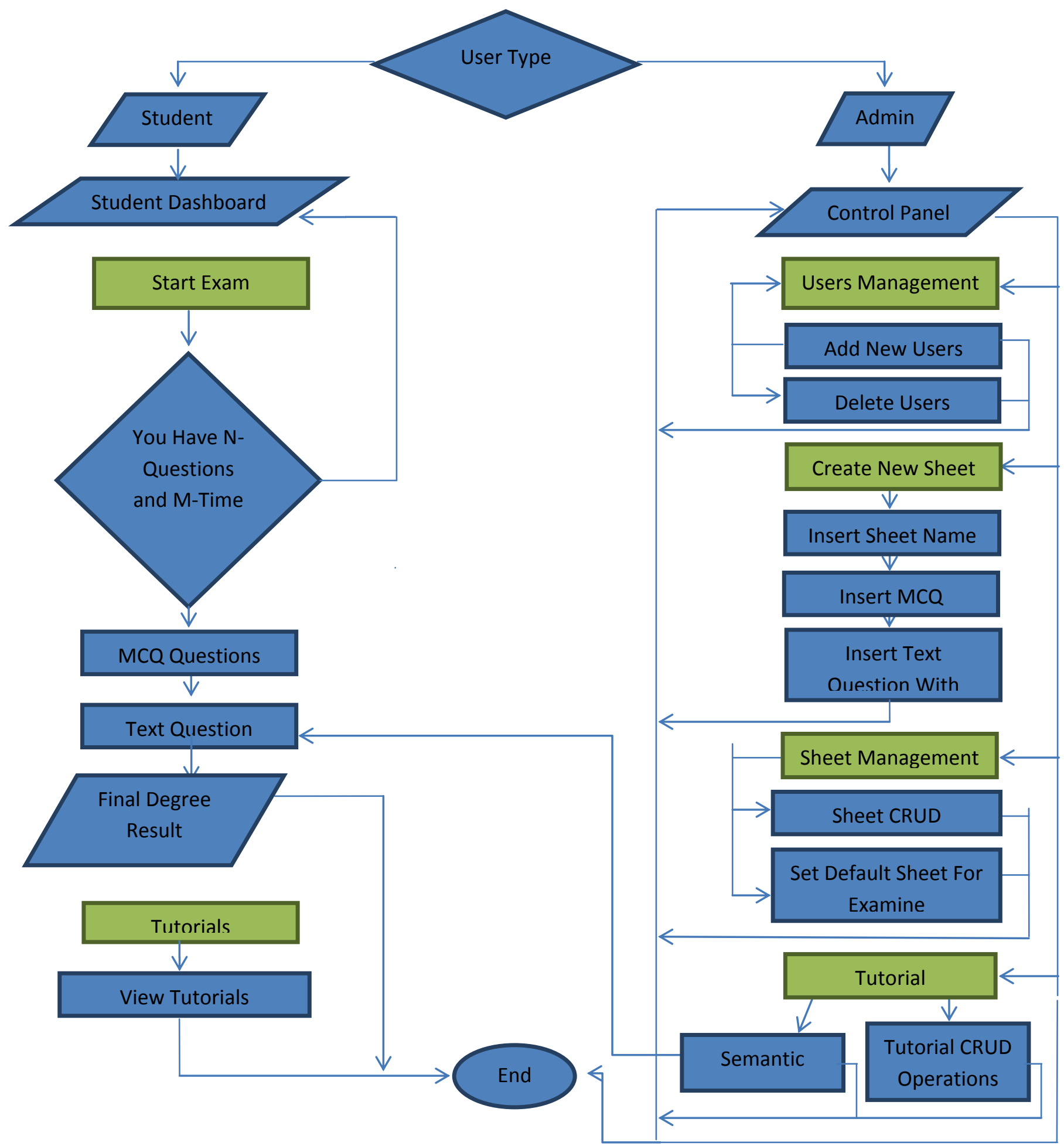

Figure (2): Main algorithm system

\section{CONCLUSIONS AND FUTURE WORK}

From the test results given in the previous chapter the following conclusions are derived:

- One major benefit observe is that the ripeness of students have smart phone, so their learning and teaching was the use of mobile devices to provide speedy, anytime, and easy access to current regular information at the point-ofcare.
- The software used it have ability for developing, updating modifying, and appending. That is given more importance to proposed system.

- This tool, established on a web interface is designed to be applied in an online environment, both by the student (the self learn and exam) and teacher (the modifying lessons and exam). The automatic evaluation process is based on experiment techniques using latent semantic processing. 
- LSA behavior is similar to human behavior, but the results are various due to non-discrimination between the terms which the general meaning of the text are depending on them and other terms in text.

\section{Suggestions}

1. Combine proposed system with knowledgebases similarity measures (WordNet) as database instead of the corpus.

2. Append other factors for final equation of similarity score such as, the order terms in sentence and weight for terms which the sentence meaning are depends on them.

\section{REFERENCES}

[1] Helen Farley and Angela Murphy "Developing a framework for evaluating the impact and sustainability of mobile learning initiatives in higher education" Australian Digital Futures Institute, University of Southern Queensland, Toowoomba, Australia, 2012.

[2] "Mobile Learning Basics" available at http://www.Mobl21.com

[3] Latent Semantic Analysis as Method for Automatic Question Scoring David Tobinski1 and Oliver Kraft2 1 University at Duisburg Essen, University atsstra_e 2, $45141 \quad$ Essen $\quad$ david.tobinski@uni-due.de,
www.kognitivismus.de.

[4] Jacqueline Bichsel, "The State of E-Learning in Higher Education: An Eye toward Growth and Increased Access" EDUCAUSE Center for Analysis and Research, 2013.

[5] Romana Martin "M-learning and student engagement: Factors that support students' engagement in m-learning" Ph.D. thesis, Murdoch University, Australia, 2011.

[6] Razieh Niazi and Qusay H. Mahmoud, "Design and Development of a Device Independent System for Mobile Learning ", the $3^{\text {rd }}$ conference on Mobile and Computer Aided Learning, IMCL2008n , 16-18 April , Amman, Jordan.

[7] L.E. Dyson, R. Raban, A. Litchfield and E. Lawrence, " Embedding Mobile Learning into Mainstream Educational Practice: Overcoming the Cost Barrier", the $3^{\text {rd }}$ conference on Mobile and Computer Aided Learning , IMCL2008n , 16-18 April , Amman , Jordan.

[8] Karim Q. Hussein , Maha A. Al-Bayati, "Mobile Learning: The Effective Role of Multimedia "Analytical Approach via an Object Oriented Strategy", International Journal of Computer Applications (0975 - 8887), New York , U.S.A, Volume 90 - No 8, March 2014 